\title{
Comparing family members' motivations and attitudes towards genetic testing for hereditary breast and ovarian cancer: a qualitative analysis
}

\author{
Caroline Dancyger ${ }^{\star, 1}$, Jonathan A Smith ${ }^{2}$, Chris Jacobs ${ }^{3}$, Melissa Wallace ${ }^{1}$ and Susan Michie ${ }^{1}$
}

Genetic testing for hereditary breast and ovarian cancer reveals significant risk information regarding one's chances of developing cancer that has potential implications for patients and their families. This study reports on the motivations and attitudes of index patients and their relatives towards genetic testing for hereditary breast and ovarian cancer. In total, 10 female index patients and 20 of their relatives were interviewed regarding their experiences of communicating genetic information within their families, and their motivations and attitudes towards genetic testing. The analysis found two types of 'family groups': groups strongly committed to genetic testing and groups uncertain about testing. Within committed family groups, index patients and their relatives felt obliged to be tested for others, leading some relatives to be tested without having fully thought through their decision or the implications of knowing their mutation status. These family groups also described considerations in relation to the value of testing for themselves. In family groups uncertain about testing, relatives had not attended for predictive testing, had postponed decision making until some point in the future or had expressed ambivalence about the value of testing for themselves. Results suggest the value of explicitly acknowledging motivations for genetic testing within the context of family obligations, relationships and communication, and the possible value of involving family members in genetic counselling and decision making from a family's first contact with genetic services. European Journal of Human Genetics (2010) 18, 1289-1295; doi:10.1038/ejhg.2010.114; published online 21 July 2010

Keywords: genetic testing; family communication; hereditary breast and ovarian cancer; motivations; attitudes; qualitative

\section{INTRODUCTION}

Genetic testing for hereditary breast and ovarian cancer (HBOC) reveals significant risk information and has potential implications for both patients and their families. In the United Kingdom, genetic testing for $\mathrm{HBOC}$ is only offered to individuals with a strong family history of cancer, in which there is at least a $20 \%$ chance of finding a cancer predisposing gene mutation. ${ }^{1}$ For an unaffected person to be eligible for a genetic test for cancer predisposition, a pathogenic mutation first needs to be identified in a relative with cancer; the 'index patient'.

At genetic counselling, it is suggested that individuals found to carry a BRCA1/2 mutation may wish to inform relatives of the result and the availability of screening and predictive genetic testing, thereby having a central role in facilitating informed decision making and risk management options for others. Thus, the genetic status of an individual has biological, psychological and relational implications for family members.

The existing literature on motivations and decision making in genetic testing is largely explored in isolation from the family context and without consideration of the influence that family communication and relationships may have on individuals. Research suggests that family communication of genetic risk information is highly selective, with regard to both what is told and to whom, which may influence the decisions of relatives to seek treatment or screening. ${ }^{2}$ Family processes are known to be an inherent part of individual decision making, ${ }^{3-5}$ and testing in one family member may influence decision making in, and the motivations of, another. ${ }^{6}$

Index patients initiating a BRCA1/2 mutation search often do so to learn about risks to their children and provide information to facilitate screening and risk management for self and family. ${ }^{7-11}$ Individuals eligible for predictive testing have also reported mixed motivations, thinking of both themselves and others when considering testing. ${ }^{12}$ However, these studies have analysed motivations from the perspectives of either the patients or the relatives; none have analysed the perspectives of both index patients and relatives within the same families.

Understanding the motivations and decision-making processes within families is of particular significance, as uptake of genetic counselling and testing by eligible family members is low. ${ }^{13,14}$ Genetic information can be very detailed and complicated, and misconceptions about inheritance and genetics abound in the public consciousness. ${ }^{15}$ Information given to patients by clinicians will be assimilated with preexisting knowledge about genetics when being conveyed to family members. These individual understandings will not only inform the decision making of patients attending genetic clinics but will also inform the decisions made by their relatives regarding their own genetic counselling and testing.

This study aimed to investigate the attitudes and motivations of both index patients and their relatives towards genetic testing and the influence of family communication and relationships upon 
their motivations. This is essential knowledge if genetic services are to effectively facilitate individual choice and informed decision making.

\section{METHODS}

\section{Participants}

Eligible index participants were female patients affected by breast or ovarian cancer who met clinic eligibility criteria and had received a positive result from a BRCA1/2 mutation search. All index patients were recruited from one of two participating National Health Service clinical genetics services in London, UK. Patients were recruited after blood had been taken for testing but before receiving their test result. Relatives recruited by the index patient were genetically related to the index patient but the degree of genetic relatedness was not specified. The index patient had to have informed them of their genetic test result but it was not necessary for the relative to have undergone predictive testing. All participants were $>18$ years of age and spoke English. As the level of analysis was the 'family group', only families in which the index patient and two relatives were interviewed were included in the analyses. In total, 10 family groups were interviewed. The demographic information is presented in Table 1. Names have been changed to protect confidentiality.

\section{The interviews}

Interviews were conducted from 2006 to 2008 . They lasted approximately $1 \mathrm{~h}$ and were semistructured, starting with a schedule but probing important topics as they arose. The interviews of index patients took place approximately 1 month after test result consultations. They were asked about their understanding of their genetic risk and were asked to describe their decision-making process with regard to communicating information to relatives. If they had revealed their test result to another family member, they were asked how and what information was given and how it was received. If patients said that they had shared the test result with at least two biological family members, they were requested to invite those relatives to take part in the study. It was up to the index patients to decide which, if any, relatives they invited. Relatives wishing to take part contacted the researcher and were interviewed up to 9 months after the interview of the index patient. They were asked to relay what they were told by the index patient, how they reacted to the information, how they perceived their own risk and whether they intended to do anything as a result of gaining this information.

\section{Data analysis}

Analytic methods were developed to examine the experiences of the participants. The first step used interpretative phenomenological analysis (IPA), ${ }^{16}$ an idiographic approach concerned with the close examination of each individual case to understand how participants make sense of their personal experience. Detailed attention was given to analysing a single case before moving to the next one. Themes were developed first in each individual in one family before examining themes across family members, which led to the generation of family-group themes represented in matrices. ${ }^{17}$

Having conducted in-depth analysis for three family groups, we examined them together. This established major inductive thematic categories, which provided a framework ${ }^{18}$ for the analysis of the remaining seven groups. Subsequent analysis produced a cross-family thematic category, which was cross-checked against individual matrices, thus capturing considerable detail for each individual participant and the context of within- and cross-family connections. This paper presents the results of one category: motivation for testing. Themes in this category are described and illustrated with extracts from participants.

\section{RESULTS}

The analysis revealed that the 10 family groups formed two distinct groupings: family groups who showed strong commitment to, and motivations for, genetic testing and family groups who were uncertain about testing. Different themes emerged for these two groupings. A transcription key for extracts in the results is provided in the Appendix.
Table 1 Demographics of the family groups

\begin{tabular}{|c|c|c|c|}
\hline & Index patient (IP) & Relative 1 & Relative 2 \\
\hline \multicolumn{4}{|l|}{ Family 1} \\
\hline Name (age) & Angela (55) & Zoe (28) & Ruth (50) \\
\hline Relationship to IP & & Daughter & Sister \\
\hline Mutation status & BRCA1 & Untested & Untested \\
\hline Cancer diagnosis & Ovarian & - & Breast \\
\hline \multicolumn{4}{|l|}{ Family 2} \\
\hline Name (age) & Sarah (38) & Laura (50) & Katie (38) \\
\hline Relationship to IP & & Sister & Niece \\
\hline Mutation status & BRCA2 & BRCA2 & Negative \\
\hline Cancer diagnosis & Breast & - & - \\
\hline \multicolumn{4}{|l|}{ Family 3} \\
\hline Name (age) & Margaret (60) & Anna (41) & Jill (55) \\
\hline Relationship to IP & & Daughter & Cousin \\
\hline Mutation status & BRCA2 & BRCA2 & Negative \\
\hline Cancer diagnosis & Breast $\times 2$ & - & Ovarian \\
\hline \multicolumn{4}{|l|}{ Family 4} \\
\hline Name (age) & Rose (71) & Joanna (33) & Lucy (34) \\
\hline Relationship to IP & & Daughter & Niece \\
\hline Mutation status & BRCA1 & Awaiting result & Untested \\
\hline Cancer diagnosis & Breast and ovarian & - & - \\
\hline \multicolumn{4}{|l|}{ Family 5} \\
\hline Name (age) & Phillipa (64) & Thomas (39) & Edward (35) \\
\hline Relationship to IP & & Son & Son \\
\hline Mutation status & BRCA2 & Negative & Negative \\
\hline Cancer diagnosis & Breast & - & - \\
\hline \multicolumn{4}{|l|}{ Family 6} \\
\hline Name (age) & Claire (64) & Helen (65) & John (60) \\
\hline Relationship to IP & & Sister & Brother \\
\hline Mutation status & BRCA1 & BRCA1 & Awaiting result \\
\hline Cancer diagnosis & Breast and ovarian & Mouth & - \\
\hline \multicolumn{4}{|l|}{ Family 7} \\
\hline Name (age) & Joan (63) & James (37) & Simon (35) \\
\hline Relationship to IP & & Son & Son \\
\hline Mutation status & BRCA2 & Untested & Untested \\
\hline Cancer diagnosis & Ovarian & - & - \\
\hline \multicolumn{4}{|l|}{ Family 8} \\
\hline Name (age) & Alice (43) & Danielle (20) & Judy (37) \\
\hline Relationship to IP & & Daughter & Cousin \\
\hline Mutation status & BRCA1 & Untested & Untested \\
\hline Cancer diagnosis & Breast & - & - \\
\hline \multicolumn{4}{|l|}{ Family 9} \\
\hline Name (age) & Elizabeth (34) & Teresa (22) & Marie (21) \\
\hline Relationship to IP & & Sister & Sister \\
\hline Mutation status & BRCA1 & Untested & Untested \\
\hline Cancer diagnosis & Breast & - & - \\
\hline \multicolumn{4}{|l|}{ Family 10} \\
\hline Name (age) & Rachel (63) & Tara (26) & Sophie (29) \\
\hline Relationship to IP & & Daughter & Daughter \\
\hline Mutation status & BRCA1 & Untested & Untested \\
\hline Cancer diagnosis & Breast and ovarian & - & - \\
\hline
\end{tabular}




\section{Family groups strongly committed to testing}

Of the 10 family groups, 7 described a strong commitment to genetic testing. Within these family groups, all interviewed relatives had either undergone predictive testing or expressed a strong intention to be tested in the future. Three themes emerged: obligation to be tested; not fully thought through; and testing for oneself.

Obligation to be tested. Participants described a strong feeling of obligation to undergo testing for the benefit of others in the family, rather than for their own benefit. This obligation was apparent in all seven family groups committed to testing, but manifested itself in different ways. Six index patients described their motivations for genetic testing as having arisen from a desire to 'do something' to help other members of the family, particularly daughters and females in the younger generations. They spoke about wanting to know their own genetic status so that, if they were found to carry a mutation, others could then be tested and action could be taken to prevent them from developing cancer as well. Once a mutation had been identified and relatives had been informed, some relatives felt obliged and pressurized to continue the process, even if they did not want testing for themselves, but because the index patient had started the process and they felt that they 'should' continue with it.

For example, in family group 1, the index patient stated that her motivation for testing was to enable her daughters to have increased screening:

I've got daughters ... they've got daughters, as well ... if I had got it, then they could be screened. (Angela, family 1 (F1) patient, BRCA1)

She told her daughters about her mutation on the day she received her result and was keen for her daughters to 'get on with it' and be tested themselves. One daughter was aware of her mother's motivation for testing and interpreted her communication about the test result and genetic risk as nagging. This led her to try to appease her mother by agreeing to testing, although at the time of interview she had not yet attended genetic counselling:

My mum's saying, you've got to get tested, and so I said, yeah, I'll get tested, but I didn't really ... I didn't really know what to do ... she was telling me to have this test done, and I was like, yeah, yeah, I'll have it done ... She wants us to have that test. (Zoe, F1 daughter, untested)

Zoe's experience of obligation was further highlighted by her concern for her own daughter's well-being and the impact a mutation in the family may have on her:

We were just concerned about our kids ... if I didn't have my daughter ... I might not ... I would like to know if my daughter's got a chance of ... and then perhaps when she has kids, there might be a way of preventing it from passing on.

This illustrates the reciprocal nature of the obligation felt between mothers and daughters, and how this may be carried on through generations, as daughters become mothers themselves. Mothers were tested to provide knowledge and opportunities for their daughters. If they were found to carry a mutation, their daughters felt obliged to be tested to continue what their mothers had started for them.

Within family group 2, the close relationship between the index patient and her sister motivated each of them to be tested for the other. The index patient was tested for her sisters and daughter. Her sister, certain that she would not carry the mutation, agreed to be tested with the hope of reducing concern in the index patient; 'she was more concerned about me having it done, me having the test'. A niece was motivated, not out of a reciprocal obligation to her aunt but to fulfil her own responsibilities as a mother. She wanted to protect her children so as not to jeopardize their rights to have their mother present throughout their childhood:

I've got two young children, so I thought I need to know, because if I do carry it and I can prevent things, then I will do whatever I have to do to do so. (Katie, F2 niece, negative)

The feeling of obligation was experienced in a different way in family group 4. An unaffected niece had started the enquiry about genetic testing, as she was concerned about her family history of ovarian cancer and her own risk. She had asked her aunt, the index patient, whether she would be tested to enable her to have predictive testing:

The only way they could start the testing was to test somebody in the family who had actually had it, and so [Lucy] spoke to me ... she had, sort of, set the ball rolling ... I'm really only doing this, you know, to help the next generation down. (Rose, F4 patient, BRCA1)

Lucy was aware of this feeling of obligation in her aunt, explaining it as a responsibility to help the rest of the family survive cancer as she had:

She's just very happy to help out. I think she feels that because she survived. She survived it and therefore she's got the responsibility to try and help the rest of us if she can. (Lucy, F4 niece, untested)

By the time a BRCA1 mutation had been identified in Rose, and Lucy was eligible to go for her own predictive testing, she was more uncertain about being tested but described feeling obliged to continue because Rose had been tested at her request:

She's gone to so much trouble ... all her sort of resources being put into it ... there is a slight responsibility on me to follow through ... I ought to carry on now and take care of myself ... when I started it all off I was partly thinking I don't really mind not knowing now but maybe in five, ten years time I will want to know and maybe in five, ten years time [Rose] won't be around to be tested ... I should get right on with it really I think, having got the result.

This belief about needing to be tested soon was not shared by Rose who considered that her test result had provided her niece with the option of being tested in the future.

Not fully thought through. Some relatives, who were motivated by feelings of obligation, quickly decided to have predictive testing, without having fully considered the consequences of knowing about their own genetic status. Although many relatives talked about the decision to be tested being easy or logical, this quick decision making sometimes led to negative emotional reactions later on when they received an unexpected result.

The decision to be tested not having been fully thought through was most strikingly observed in family group 2 . By the time both relatives were interviewed, they had found out their mutation status and neither one seemed prepared for their result. The index patient's sister 
reflected on her 'flippant' decision to be tested, which was based on an expectation that she would not be a mutation carrier. She was left in a state of indecision, uncertain of what to do as a result of her positive result, possibly trying to avoid another 'flippant' decision:

Thinking about it in hindsight, I don't think if I thought I had any chance of having it, I would've had the tests done. I really don't. I was really, really shocked. Yeah, I was quite flippant about having the tests because, ah yeah, do it ... I know I'm going to be all right (laughs). (Laura, F2 sister, BRCA2 positive)

Katie described making the decision to be tested without 'even thinking about it' and choosing to wait for the certainty of a result before considering the consequences of knowing about her mutation status:

I didn't even think about it ... didn't even question it. It was just, okay fine, I'll do it and I'll deal with whatever I've got to deal with when I know I've got to deal with it ... After I'd had it and come home, I think that's when the panic hit me and I thought, oh God, you know ... this really could happen, I could really have this ... the implications really hit me, and I think for a couple of days I probably was a bit low thinking ... worrying. (Katie, F2 niece, negative)

This extract suggests that Katie did not make an informed choice about predictive testing as she intentionally stopped herself from considering what the consequences of knowing her mutation status may have been. Her decision to be tested was made impulsively after finding out about her aunt's result and she did not give herself time to consider her decision or how she may feel until after she has been tested.

The daughter in family group 3 acknowledged a pressure from her mother to be tested as soon as possible but was aware of her need for time to decide, leading her to lie to her mother about how far along the genetic counselling process she had been:

Every time my mum phoned, I was thinking, she's going to hassle me about having those tests and I think I even lied to her and told here that I'd phoned [the genetic counselor] and she wasn't there and I'm waiting for her to call me back. (Anna, F3 daughter, BRCA2 positive)

By the time she attended genetic counselling, her mind was made up, and despite being encouraged to wait and consider her decision further, she chose to go forward with testing. Her decision was made on the risk information given to her by her mother to encourage her to get tested, rather than the accurate information given to her in the consultation:

The genetic counselor was right, you do need time to think about it, but by the time I did go and see her, I had made up my mind that I wanted the tests and even though she was persuading me, or trying to persuade me to wait a little while, I almost did wait ... then when I thought about the 40 thing again and that was unclear in my mind, I said no I want the tests now.

Testing for oneself. Five family groups who expressed a strong commitment to be tested also described positive consequences for themselves. Individual motivations were based on perceptions that awareness of one's risk would be valuable for one's health, would increase feelings of control over one's risk, body and future and provide more risk management options:

Do I really want to know the outcome of it? ... well, if the outcome is good, then it puts your mind at rest. And if it's not good, well you can do something about it. (Phillipa, F5 patient, BRCA2)

Forewarned is forearmed ... It's knowing your enemy. (Thomas, F5 son 1, negative)

Better to know ... than to bury your head in the sand. (Edward, F5 son 2, negative)

For this family group, genetic testing was seen as empowering. Knowledge was considered to be valuable; knowing was better than not knowing, providing each family member with more options to manage their health and risk.

The index patient in family group 3 was the only index patient in this group who explicitly stated her original motivation as primarily for her own benefit and did not mention feeling obliged to be tested for others. She did not regard testing as empowering, but as a way of answering questions about the cause of her own cancer and absolving her feelings of responsibility for potentially having caused her breast cancer:

I really want to know whether I have a genetic basis for this cancer ... for years I'd thought why did I get it at 37 ? What did I do wrong in my life ... did I eat the wrong foods? Did I not do enough exercise? (Margaret, F3 patient, BRCA2)

Her cousin, who had also been affected by cancer, also talked about the value of genetic testing in enabling her to find out the cause of her own cancer:

I was perhaps looking for a reason why I'd got cancer ... when this came up I thought this would explain everything. (Jill, F3 cousin, negative)

For Margaret and Jill, discovering a genetic basis for their cancer would absolve them of feelings of guilt and responsibility for having caused their cancer. However, by discovering she carried a mutation, Margaret replaced the guilt and responsibility for having caused her own cancer with guilt and responsibility for potentially having passed on a mutation to her daughter. This may explain why her daughter then felt obliged to be tested, as a negative test result would eradicate this feeling of guilt in her mother:

Obviously I'm concerned about my daughter ... I hope she hasn't inherited it from me and that's my big concern. (Margaret, F3 patient, BRCA2)

\section{Family groups uncertain about testing}

Three family groups expressed uncertainty about testing. Although all index patients had been tested and found to carry a BRCA1/2 mutation, their unaffected relatives were more hesitant about predictive testing for themselves, and at the time of interview none had undergone genetic counselling or testing. Within these groups, the index patients did not express strong motivations for testing, instead deciding to be tested, primarily because it was recommended to them by medical professionals. Two themes emerged that help in understanding the uncertainty of relatives regarding predictive testing: testing in the future and ambivalence. 
Testing in the future. A number of relatives acknowledged that, although predictive testing may be beneficial, the timing was not right for them because of their current circumstances or stage in life. In family group 10, the index patient was offered testing having been diagnosed with both breast and ovarian cancer and agreed to it to provide her children with information, without the expectation that they too would want to be tested:

It was offered to me on account of the fact that I have had breast cancer and ovarian cancer ... and I said okay, yes please ... for my children, really. So that they could be monitored ... But I leave it up to them, they're all adults (Rachel, F10 patient, BRCA1)

With no pressure placed on them to get tested, neither of Rachel's daughters had had predictive testing at the time of interview. Tara saw the benefits of testing but did not feel it was right for her at the time, as she was pregnant:

I don't really want to go for any testing just yet, I'll wait, you know, wait for a few months after I've had [child] number two, and, and then I will go for the screening and the counseling. (Tara, F10 daughter 1, untested)

Although Tara was largely positive about testing and could see the benefits of knowing and managing her risk, her sister was less convinced. Sophie struggled to see the added value of knowing her mutation status and saw little she could do about her risk:

It doesn't really mean that much because you still don't really know you're going to get it ... it's not really going to help you ... Information that is a little bit scary but not amazingly useful. (Sophie, F10 daughter 2, untested)

However, she acknowledged that this was her current perception of the value of testing, as a young woman in her 20 s with little concern about her health, but that her perception of the value of testing or her desire to be tested may change over time:

It's not really something I need to know right now. But maybe it will change ... I'm just really busy ... it's not top of my list of things to worry about or to go and do ... I don't have health issues on the mind at the moment but I guess when I'm forty or fifty those, my mind will probably be a bit more concerned about these things.

The understanding of both daughters of the risk information received from their mother was limited. No one in the family group felt concerned about the mutation or their risks, perhaps as a result of the low prevalence of cancer in the family and their beliefs in environmental triggers to cancer.

The two daughters in family group 10 did not feel that the time was right for them to be tested because of their life stages. However, in family group 8 , a cousin remained undecided about testing, not because of her own stage of life but because of the age of her daughter. Judy considered the impact on her daughter if she was found to carry a mutation. She felt that, because of the open communication in her family, it would be difficult to keep this information from her daughter, but did not think that it was a good time for her daughter to find out about genetic risk:

That's the side puts me off from having the test, it's the knockon effect for your children ... When you look at the kids at their ages and you think, you know, they're going to be armed with that information now... it's a lot for them to take on at that age. (Judy, F8 cousin, untested)

She expressed how if she had not had children, she would have been tested immediately, but her concerns about how her daughter would cope delayed her decision to be tested:

If it was me on my own I would have the test done without question ... but because my daughter's 12, once I know that result, if it's not a good result, then she's going to know that.

Ambivalence. Within 'uncertain' family groups, there were expressions of ambivalence about testing in relatives, which left them in a state of indecision.

For Judy in family group 8, putting off making decisions until she believed her daughter would be ready to find out about her carrier status contributed to her ambivalence about the value of testing. Her perception of when it would be good for her daughter to find out was prioritized above the value of knowing her mutation status for herself:

I'm sure, at some point, I will have it done .... But when, I don't know ... I think if it was me on my own I'd definitely have it done, but it's just the implications with my daughter. (Judy, F8 cousin, untested)

Another reason why she was reluctant to undergo predictive genetic testing was because it would not assist with her perception of risk. This is in opposition to the motivations of Alice, the index patient, who was tested to manage her own risk of future cancer:

If I've got a faulty gene in my body, that's why I've had breast cancer ... I'm going to do everything I can to stop it [the cancer] coming back. (Alice, F8 patient, BRCA1)

Judy already felt at risk for breast cancer as a result of her mother's experience with cancer. She felt burdened with a sense of risk regardless of whether she had a predictive test and regardless of what the result of the test would be:

If you've been tested and you've got your result and it's negative ... what happens in 10 years' time if they find more genes, you know? Are you back down that route again, that you thought you were fairly safe, and then you're not?

This burden of risk was reflected in the experiences of family group 9, in which a strong family history of breast cancer led to heightened shared anxiety about cancer. The index patient felt this anxiety but based her decision to be tested on clinical recommendation:

The doctors have said that it was good to know so they can go for all the check-ups. (Elizabeth, F9 patient, BRCA1)

Ambivalence around predictive testing in her sisters reflected a dilemma between being proactive and confronting the cancer risk and avoiding any association with cancer or increased anxiety. Marie clearly articulated this:

It is really scary ... but it's good to know as well. (Marie, F9 sister 2, untested) 
This ambivalence was intensified by uncertainty over what could be done if a mutation was identified. Without fully understanding the benefits of testing, the anxiety associated with finding out her mutation status maintained her reluctance to be tested:

I will do it soon, it's better to know at the end of the day ... I don't know how to prevent it, there isn't a way ... I don't know what to think about me doing it ... it's not something I would go out of my way to try and find out or to try and do.

Ambivalence over the value of testing was shared by Teresa, who, although expressing the view that it was better for the family (including herself) to know more about their genetic risk, was confused and unable to express clearly what the value would be in knowing more:

I thought it was a good idea ... Um, early detection and, you know, take steps to ... you can't avoid it, or you can ... well if you do find out early enough you can do something, I don't know. (Teresa, F9 sister 1, untested)

Teresa also expressed knowledge in negative terms. In the extract below, she suggests that it was her sister's discovery of her genetic status that placed the family at risk, rather than the risk existing before the knowledge of it. Knowledge made the risk a reality and invoked fear and anxiety and therefore knowledge was perceived by her as undesirable:

We hoped it was going to just pass by and stuff; but as she has it now, maybe we might also have it.

\section{DISCUSSION}

All 'committed' family groups described their primary motivations for testing as arising from an obligation to others, while also acknowledging some, but less strong, motivations to be tested for their own benefit. This supports previous research suggesting that people decide to undergo genetic testing on the basis of a combination of acting for oneself and for others. ${ }^{5,12}$ This obligation to others can be considered in terms of genetic responsibility: to do what is morally right for the family. ${ }^{3}$ It has been argued that this may be particularly pertinent for women, whose identities are constructed as a self-in-relation to others and defined by their roles as mother, wife or sister. ${ }^{19}$ Of central importance to a woman's responsibility is the welfare of her close relatives, which may come before her own well-being. Thus, by being tested for others, she is doing what responsible 'ordinary' women would do. ${ }^{11}$ Men have also been seen to undergo testing because of family obligations, ${ }^{14,20,21}$ and the few male relatives interviewed in our study also acknowledged this obligation in their motivations for testing, suggesting that genetic responsibility may not be a gendered responsibility.

The burden of genetic responsibility may extend beyond the individual being tested, to related family members who are seen as also being obligated to know and act responsibly in relation to their genetic risk. ${ }^{5}$ Our results support this reciprocal notion of responsibility, as relatives described an obligation to act on the genetic information given to them by the index patient by having their own predictive testing. This resulted in some relatives feeling pressurized to be tested to fulfil their genetic responsibility, despite feeling unsure about the value of predictive testing. Thus, familial obligation may override the perception of the value of testing for oneself in some cases. Feelings of guilt and blame for putting one's children at risk and passing on a mutation have been well reported, ${ }^{20,22}$ and it may be that these feelings underlie the obligations of mothers to be tested and their obligations to motivate their daughters to be tested as well. By interviewing multiple members of the same family, we have shown examples of reciprocal obligation. This is an innovative way of exploring family relationships, illuminating how family dynamics influence the individual's motivations.

Motivations to be tested do not have to be an either/or process: feeling obliged to be tested for others versus individual agency. As our results show, these two motivations can coexist, with people exercising individual agency through their responsibility to others. ${ }^{20}$ Researchers ${ }^{10,23}$ have suggested the concept of an interdependent self, in which the needs of others are seen as an integral part of the self rather than the self being construed as an autonomous agent. Doing for others is in essence doing for oneself. This may provide a more accurate way of understanding decision making about genetic testing than the traditional individualistic conception of the self making rational autonomous decisions.

Three of our family groups were less committed to genetic testing. In these family groups, none of the unaffected relatives had undergone, or made decisions about, predictive testing, and all were uncertain about the value of knowing their mutation status. There has been little previous investigation of why people decline/defer testing in clinical populations, as these individuals do not come into contact with genetics services and are therefore difficult to recruit. However, through asking our index patients to recruit their relatives to the study, we have been able to gain access to such individuals. Our results suggest that age and life stage of a relative may be factors that inhibit uptake of predictive genetic testing, supporting the notion that developmental concerns have a significant role when considering the timing of genetic testing. ${ }^{24}$ This is consistent with the little previous research that has been conducted, which suggests that relatives who decline/defer testing may do so because they are not yet ready to take a BRCA1/2 test, they do not yet have children whom they feel obliged to pursue testing for and/or because of their lesser concerns for their own health as they have not yet reached the age of greatest HBOC risk. ${ }^{13,14,25}$ Such factors may lessen the perceived benefits of testing for self and others and consequently reduce interest in taking the test.

For one of our family groups, the two young female relatives were ambivalent about the value of predictive testing, as confronting their cancer risk head-on would have led to increased fear and anxiety, which they tried to avoid. Their ambivalence was compounded by uncertainty over options if they were found to be mutation carriers. This illustrates how appraisals of the perceived benefits of testing may interact with emotional factors such as fear and anxiety, leading to ambivalence and a delay in the decision to be tested. This lends support to the idea that pursuing genetic testing may not only be a way of managing risk but also a way of coping with the stress of being at heightened risk of cancer. ${ }^{26}$ Emotional motivators of health behaviour are rarely considered, ${ }^{27}$ but our results suggest that women motivated to avoid extra fear and anxiety may decide to defer testing because of its potential to reveal threatening information that may outweigh the perceived advantages of testing. Notably, these participants were in their early 20s, supporting the idea that life stage affects how genetic information is perceived. Given the degree of uncertainty around the meaning of test results reported in some of the family groups in this study, we think it would be valuable for genetic counsellors to help index patients to consider how they might communicate the implication of test results with their families.

Our results suggest the value of discussion of motivations for testing and exploring feelings of obligation during genetic counselling. 
Discussing the impact that results may have on other family members' feelings of duty and responsibility and their attitudes towards receiving genetic information and knowing their own risk status may be beneficial before testing. This may reduce the likelihood of relatives agreeing to predictive testing out of obligation without a full understanding of the consequences for themselves and then experiencing negative emotional reactions when they receive an unexpected result. It may also prepare patients motivated to undergo testing for others for the reactions of those relatives who choose to decline or defer testing. This may be particularly important in situations in which relatives are younger adults or in which they have coped with anxiety regarding cancer through avoidance.

We recognize the impact of the self-selection of participants on our findings. Index patients approached relatives with whom they had a good relationship and/or whom they thought would be willing to take part in the study. We cannot assume that our results would apply to all members of these families or to all families involved in genetic testing. We also recognize that over time there may be changes in both the 'strongly committed' and 'uncertain' family groups as relatives age, have their own children or glean more information about testing.

If motivation arises from familial obligation, then decision making around testing may benefit from being explicitly considered as a family matter. Clinicians may want to consider the value of framing decision making in this context and encourage family discussion from the outset. This may facilitate an assessment of the educational and support needs of all members of the family, including relatives who decline/defer testing and who may not approach genetic services. However, although genetic testing is a family matter, the individual needs and preferences of patients remain the foundation of clinical guidelines in the United Kingdom. The personal implications and value of testing, which may be influenced by factors such as age, life stage and anxiety, need to be addressed in genetic counselling, along with the implications for the family. This balance is a difficult one to achieve but may be best realized through viewing the patient as an interdependent self and their decision making as occurring within the context of their family relationships.

\section{CONFLICT OF INTEREST}

The authors declare no conflict of interest.

\section{ACKNOWLEDGEMENTS}

This study was funded by the UK Department of Health Grant (HSR06). We thank the genetics services for help in recruitment and the patients and relatives who participated.

1 McIntosh A, Shaw C, Evans G et al: Clinical Guidelines and Evidence Review for the Classification and Care of Women at Risk of Familial Breast Cancer. London: National Collaborating Centre for Primary Care/University of Sheffield. NICE guideline CG014, 2004, updated 2006.
2 Gaff CL, Clarke AJ, Atkinson P et al: Process and outcome in communication of genetic information within families: a systematic review. Eur J Hum Genet 2007; 15: 999-1011.

3 Hallowell N: Doing the right thing: genetic risk and responsibility. Sociol Health IIIn 1999; 21: 597-621.

4 Smith JA, Michie S, Stephenson M, Quarrell O: Risk perception and decision-making processes in candidates for genetic testing for Huntington's disease: an interpretative phenomenological analysis. J Health Psychol 2002; 7: 131-144.

5 Etchegary H, Miller F, Delaat S, Wilson B, Carroll J, Cappelli M: Decision-making about inherited cancer risk: exploring dimensions of genetic responsibility. J Genet Couns 2009; 18: 252-264.

6 Jacobs LA, Deatrick JA: The individual, the family and genetic testing. J Prof Nurs 2009; 15: 313-324.

7 Lerman C, Croyle R: Psychological issues in genetic testing for breast-cancer susceptibility. Arch Intern Med 1994; 154: 609-616.

8 Hallowell N, Foster C, Eeles R, Ardern-Jones A, Murday V, Watson M: Balancing autonomy and responsibility: the ethics of generating and disclosing genetic information. J Med Ethics 2003; 29: 74-79.

9 Mellon S, Berry-Bobovski L, Gold R, Levin N, Tainsky M: Family communication and decision making regarding inherited breast/ovarian cancer risk information. Oncol Nurs Forum 2005; 32: 193.

10 d'Agincourt-Canning L: Genetic testing for hereditary breast and ovarian cancer: responsibility and choice. Qual Health Res 2006; 16: 97-118.

11 Rowley E: On doing 'being ordinary': women's accounts of BRCA testing and maternal responsibility. New Genet Soc 2007; 26: 241-250.

12 Foster C, Watson M, Moynihan C, Ardern-Jones A, Eeles R: Genetic testing for breast and ovarian cancer predisposition: cancer burden and responsibility. $J$ Health Psychol 2002; 7: 469-484.

13 Landsbergen K, Verhaak C, Kraaimaat F, Hoogerbrugge N: Genetic uptake in BRCAmutation families is related to emotional and behavioral communication characteristics of index patients. Fam Cancer 2005; 4: 115-119.

14 Finlay E, Stopfer JE, Burlingame $\mathrm{E}$ et al: Factors determining dissemination of results and uptake of genetic testing in families with known BRCA1/2 mutations. Genet Test 2008; 12: 81-91.

15 Durant J, Hansen A, Bauer M: Public understanding of the new genetics; in Marteau TM, Richards M (eds): The Troubled Helix: Social and Psychological Implications of the New Human Genetics. Cambridge: Cambridge University Press, 1999, pp 235-248.

16 Smith JA, Flowers P, Larkin M: Interpretative Phenomenological Analysis. London: Sage, 2009

17 Miles MB, Huberman AM: Qualitative Data Analysis: An Expanded Sourcebook, (2nd edn). London: Sage, 1994.

18 Ritchie J, Spencer L: Qualitative data analysis for applied policy research; in Bryman A, Burgess R (eds): Analyzing Qualitative Data. London: Routledge, 1994, pp 173-194.

19 Gilligan C: In a Different Voice: Psychological Theory and Women's Development. London: Harvard University Press, 1982.

20 Hallowell N, Arden-Jones A, Eeles R et al: Guilt, blame and responsibility: men's understanding of their role in the transmission of BRCA1/2 mutations within their family. Sociol Health IIIn 2006; 28: 969-988.

21 Hallowell N, Ardern-Jones A, Eeles R et al: Communication about genetic testing in families of male BRCA1/2 carriers and non-carriers: patterns, priorities and problems. Clin Genet 2005; 67: 492-502.

22 Lynch HT, Snyder C, Lynch JF et al: Patient responses to the disclosure of BRCA mutation tests in hereditary breast-ovarian cancer families. Cancer Genet Cytogenet 2006; 165: 91-97.

23 Kenen R: The human genome project: creator of the potentially sick, potentially vulnerable and potentially stigmatised?; in Robinson I (ed): Life and Death Under High Technology Medicine. Manchester: Manchester University Press, 1994, pp 49-64.

24 Hamilton R, Williams JK, Bowers BJ, Calzone K: Life trajectories, genetic testing and risk reduction decisions in 18-39 year old women at risk for hereditary breast and ovarian cancer. J Genet Counsel 2009; 18: 147-159.

25 Foster C, Evans DGR, Eeles R et al: Non-uptake of predictive genetic testing for BRCA1/2 among relatives of known carriers: attributes, cancer worry, and barriers to testing in a multicenter clinical cohort. Genet Test 2004; 8: 23-29.

26 Gooding HC, Organista K, Burack J, Biesecker BB: Genetic susceptibility testing from a stress and coping perspective. Soc Sci Med 2006; 62: 1880-1890.

27 Shiloh S, Ilan S: To test or not to test? Moderators of the relationship between risk perceptions and interest in predictive genetic testing. J Behav Med 2005; 28: 467-479.

\section{APPENDIX \\ TRANSCRIPTION NOTATIONS}

... Indicates editorial elision in which non-relevant material has been omitted. [text] Indicates explanatory text added by authors.

F stands for family in transcript identifier; F1 is family 1. 